\title{
Cure Kinetics and Activation Energy Studies of Modified Bismaleimide Resins
}

\author{
M. Satheesh Chandran, ${ }^{1}$ M. Krishna, ${ }^{1}$ Sheshappa Rai, ${ }^{2}$ M. S. Krupashankara, ${ }^{1}$ and K. Salini ${ }^{1}$ \\ ${ }^{1}$ Research and Development, Department of Mechanical Engineering, R. V. College of Engineering, Bangalore 560 059, India \\ ${ }^{2}$ Department of Polymer Science, University of Mysore, Karnataka 570005, India
}

Correspondence should be addressed to M. Satheesh Chandran, satheeshchandran.m@gmail.com

Received 11 December 2011; Accepted 11 January 2012

Academic Editors: A. Buzarovska and A. Mousa

Copyright () 2012 M. Satheesh Chandran et al. This is an open access article distributed under the Creative Commons Attribution License, which permits unrestricted use, distribution, and reproduction in any medium, provided the original work is properly cited.

The cure kinetics and activation energy (Ea) of bismaleimide homopolymer and modified bismaleimide resin systems with different chain extenders were investigated. The bismaleimide resin under investigation was bismaleimidodiphenyl methane (BMPM) and the chain extenders were (i) O-O' diallyl bisphenol A (DABA) and (ii) methylenedianiline (MDA). Dynamic multiheating DSC method was used to study the kinetics of the curing process. Activation energies were determined for both unmodified and modified resins from nonisothermal multiheating rate DSC tests by using Ozawa and Kissinger models. Activation energy for BMPM homopolymer increased from $95 \mathrm{~kJ} / \mathrm{mol}$ to $125 \mathrm{~kJ} / \mathrm{mol}$ as a function of conversion. For the MDA-modified system the activation energy was independent of percentage conversion, at $108 \mathrm{~kJ} / \mathrm{mol}$. In the case of DABA-modified bismaleimide the activation energy increased steadily at $6 \mathrm{~kJ} / \mathrm{mol}$ from 10 to $100 \%$ conversion.

\section{Introduction}

High performance thermosets are of great interest as matrix resin for composites. Bismaleimide- (BMI-) and Polyimide(PI-) based systems are among the more thermally stable thermosetting resins that are fast replacing the widely used epoxy resins. The unique properties of BMI resins, such as low moisture absorption, high crosslink density, good chemical resistance, and high glass transition temperature (Tg) make these resins suitable for prepregs, adhesives, electrical packaging, and other composite applications [13 ]. The properties they exhibit are directly related to the microstructure, with high cross-linking density, inherent aromatic structure and rigid molecular network. However, these microstructural characteristics results in inherent brittleness of the material. Extensive research is being done to enhance the toughness of BMIs by reducing the crosslink density, methods include the addition of reactive elastomers, copolymerization with allyl terminated copolymer, eutectic mixtures and modification with thermoplastics, or a combination of these methods [4].
According to the principles of molecular design, introducing a flexible linkage or chains into BMI can effectively improve the toughness of the resin [5], and the most preferred method for BMI resin modification is the copolymerization with allyl functional compounds and Michel addition chain reactions with aromatic diamines. The modified BMI resins can easily replace Epoderstand and predict the cure bxy resins, since the processing conditions are similar, but with superior performance characteristics. The properties of these BMI resin systems depend on the structure, extent of cure, time, and temperature of cure. When modelling the cure kinetics of the processes, the heating rate and temperatures of the reaction should be accurately known to get better control on the final microstructure and to optimize the physical properties of the product. It is for this reason that the cure kinetics must be fully understood and optimised for the best performance characteristics of the modified resins $[6,7]$.

The objective of this work was to compare the curing kinetics of different chain extended BMI resins. The studies were focused on homopolymerisation of (i) $4,4^{\prime}$ bismleimidodiphenyl methane (BMPM), which is one of widely 
used resins in the bismaleimide (BMI) category (ii) 4,4' bismleimidodiphenyl methane (BMPM), with $\mathrm{O}^{-\mathrm{O}^{\prime}}$-diallyl bisphenol A (DABA), and (iii) 4,4' bismleimidodiphenyl methane (BMPM) with Methylenedianiline (MDA). Nonisothermal multiheating rate method was adopted to determine the kinetic response and activation energies of BMI resin systems.

\section{Experimental}

2.1. Materials. The resin systems $4,4^{\prime}$ bismleimidodiphenyl methane (BMPM) resin (Figure 1), O- $\mathrm{O}^{\prime}$-diallyl bisphenol A (DABA) (Figure 2) and methylenedianiline (MDA) (Figure 3) were procured from ABR organics (Hyderebad,India). The BMPM/DABA resin system was prepared by mixing the components in $1: 1$ molar ratio and BMPM/MDA resin system was prepared in molar ratio of $3: 2$ as specified by resin manufacturer.

2.1.1. DSC Measurements. The thermal data were obtained by using Mettler 823 differential scanning calorimeter (DSC) calibrated with an Indium standard. The thermal data of the resin was based on nonisothermal, multiheating rate method. The sample was placed in the DSC cell and equilibrated at $40^{\circ} \mathrm{C}$. The samples were heated at different heating rates $\left(5,10\right.$ and $\left.20^{\circ} \mathrm{C} / \mathrm{min}\right)$. A stream of nitrogen at a flow rate of $20 \mathrm{~mL} / \mathrm{min}$ was used to purge the DSC cell.

2.1.2. Kinetic Models. Cure kinetics of resins systems are studied using non-isothermal and isothermal methods, the former method includes a single and multi-heating rate and the later involves studying the reaction mechanism at a specific temperature as a function of time. The nonisothermal single heating rate method measures the curing process at a constant heating rate, while the multiheating rate method is an isoconversional method and is suitable for systems with multiple reactions. The two kinetic analysis models are extensively used to understand and predict the cure behaviour of the resin systems. The basic assumption for the application of DSC technique to the cure of the thermosetting resins is that the rate of kinetic process $(d \alpha / d t)$ is proportional to the measured heat flow $\Phi[7]$

$$
\frac{d \alpha}{d t}=\frac{\Phi}{\Delta H},
$$

$\Delta H$ being the enthalpy of the reaction. The rate of the kinetic process in kinetic analysis can be described by (2):

$$
\frac{d \alpha}{d t}=\mathrm{K}(T) f(\alpha)
$$

where $\alpha$ is the chemical conversion or extend of reaction and $f(\alpha)$ is assumed to be independent of temperature [7]. The rate constant is $K(T)$ is dependent on temperature and assumed to follow an Arrhenius equation:

$$
K(T)=A \exp \left(-\frac{E_{a}}{R T}\right),
$$

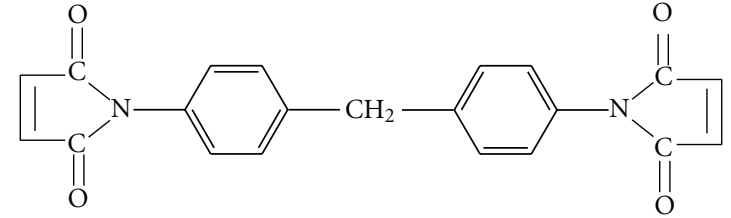

4,4'-bismaleimidodiphenylmethane(BMPM)

FIGURE 1: Chemical structure of BMI resin.

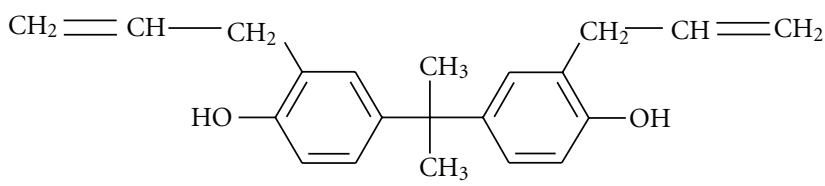

FIgURe 2: Chemical structure of O-O' diallyl bisphenol A (DABA).

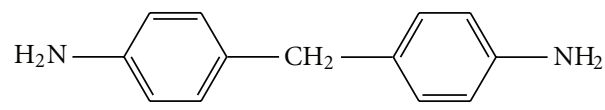

FIgURE 3: Chemical structure of methylenedianiline (MDA).

where $A$ is the preexponential factor (frequency factor) and $E_{a}$ is the activation energy. $R$ is the gas constant $(8.314 \mathrm{~J} / \mathrm{mol} / \mathrm{K})$ and $T$ is the absolute temperature. The kinetic parameters of the curing reaction, with special reference to $E_{a}$, can be calculated using different computational methods [8-11]. $E_{a}$ is determined by the isoconversional methods using the logarithmic form of the kinetic equation (2):

$$
\ln \frac{d \alpha}{d t}=\ln [A f(\alpha)]-\frac{E_{a}}{R T} .
$$

The slope of $\ln d \alpha / d t$ versus $1 / T$ for the same values of $\alpha$ gives the value of activation energy. This assumption is related to the Ozawa and Kissinger methods which relate activation energy $E_{a}$ and heating rate $\theta$ and the peak exotherm temperature $T p$ with the assumption that the extent of the reaction at the exotherm peak is constant and independent of the heating rate [12]. Researchers have also adopted the $n$th order kinetics (NOK) model and model-free kinetics (MFK) model to understand, predict and explain the cure kinetics and activation energy $[13,14]$. The NOK model is applicable to simple reactions, where the activation energy is constant thought the entire reaction. However, in the case of more complex reactions involving several reaction steps, which proceed in parallel and is not completely chemically controlled, the reaction kinetics is understood using the model-free kinetics (MFK) model. The MFK approach is based on the assumption that activation energy does not remain constant during a reaction and that the activation energy at a particular conversion is independent of the heating rate, also termed as "isoconversion principle". The MFK model also predicts that at increasing heating rates, chemical reactions take place at higher temperature and that the reaction mechanism does not change with heating rate 
[13]. In order to determine if a particular reaction follows the NOK model or the MFK model, it is required to compute the activation energy $\left(E_{a}\right)$ as a function of fractional conversion. The molar ratio of the constituents has an influence on the reaction, value of $E_{a}$, and the final structure. In the case of hot-curing systems, isothermal kinetics approach is adopted wherein the reaction kinetics changes from being chemically controlled in the liquid state to diffusion controlled in the glassy state as a function of time at a given temperature. The cross-linking reduces molecular mobility and results in the process changing from being kinetically controlled to diffusion controlled. After vitrification, the reaction becomes diffusion controlled and then practically stops at a maximum conversion, a greater conversion can only be reached by raising the reaction temperature [14].

\section{Results and Discussion}

Figure 4 shows the DSC thermograms of BMPM, BMPMDABA and BMPM-MDA at heating rates of 5, 10, and $20^{\circ} \mathrm{C} / \mathrm{min}$. These three heating rates were chosen based on the guidelines of the MFK model and in order to ensure reliable understanding of the cure kinetics. The DSC thermograms show three principal regimes: (a) BMPM neat resin and BMPM/MDA are fine crystalline powders and BMPM/DABA is a highly viscous liquid at room temperature, which upon heating melts showing an endothermic peak, (b) the second regime, is the onset of curing, which is broad and is predominantly chemically driven process, and in (c) the third regime, there is a distinct change in heat flow due to combined effect of kinetics and the inherent exothermic reaction resulting in peak temperatures. The peak maximum temperature shifts to higher temperatures with increase in heating rate due to kinetic effects. Table 1 gives the temperature values of the three principal regimes of the three resin systems under study.

The DSC plots precisely follow the assumptions stated in the MFK model. In the case of BMPM the endotherm temperature appeared exactly at $162^{\circ} \mathrm{C}$ irrespective of the heating rate; however, the magnitude of heat flow corresponding to endotherm peak was more intense at $-3,-7$, and $-10 \mathrm{~mW}$, signifying a complete melting at a heating rate of $20^{\circ} \mathrm{C} / \mathrm{min}$. As expected and tabulated in Table 1 , the peak exotherm temperature shifted to higher temperature with increase in heating rates due to kinetic effects. The percentage conversion remained constant at approximately $60 \%$ independent of heating rate, as postulated in the MFK model. However, with the inclusion of the modifiers DABA and MDA, the cure process becomes more complicated. In the case of BMPM/DABA, two endotherms are observed between 100 and $120^{\circ} \mathrm{C}$ followed by the curing exotherm, where as in the case of BMPM/MDA system a single endotherm was observed at $90^{\circ} \mathrm{C}$ followed by the curing exotherm. The shifting of the endotherm can be explained by the effect of the chain extension, which shifts the melting peak to lower temperature compared to the BMPM neat resin.

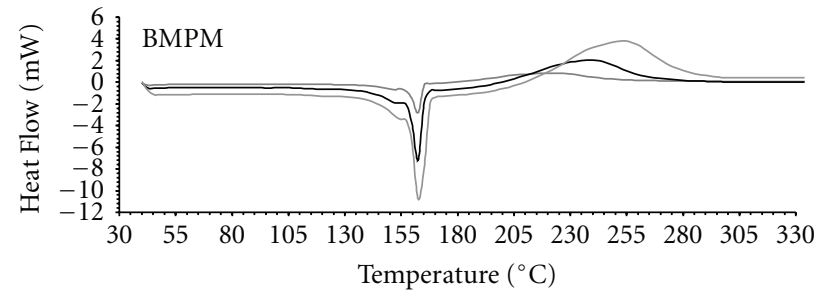

(a)

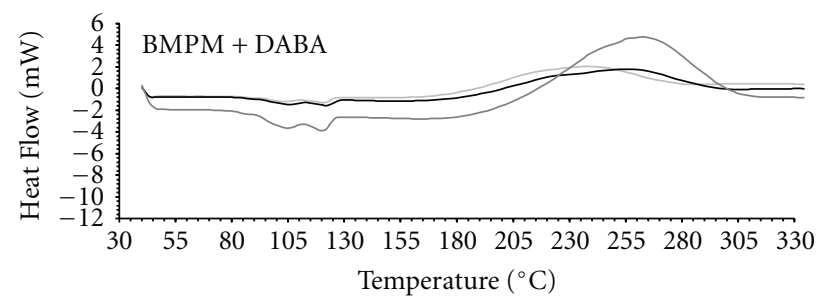

(b)

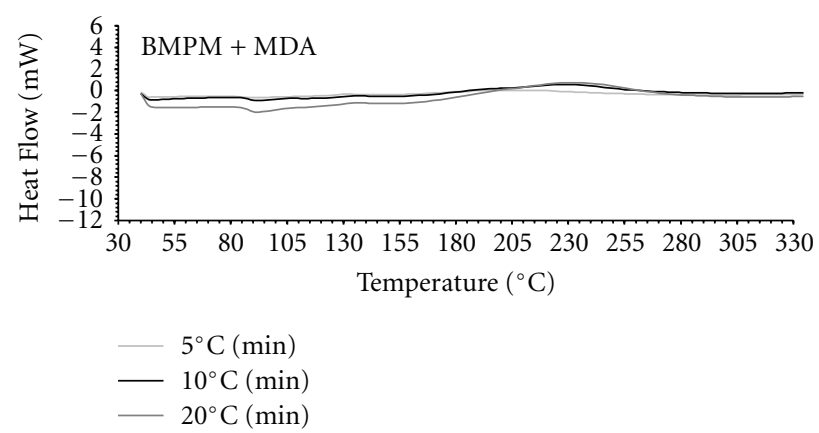

(c)

FIGURE 4: DSC plots of BMPM, BMPM-DABA, and BMPM-MDA at different heating rates.

The shift in the peak exotherm temperature as a function of heating rates is tabulated in Table 1 . The magnitude of temperature different between $5^{\circ} \mathrm{C} / \mathrm{min}$ and $20^{\circ} \mathrm{C} / \mathrm{min}$ is approximately $25^{\circ} \mathrm{C}$, however the percentage conversion at peak temperature was in the range of 55 to $59 \%$, as defined in the MFK model. The DSC curves show a distinct difference in the heat flow pattern, between the three resin systems. BMPM-DABA has a heat flow value in the range of 2 to $4.7 \mathrm{~mW}$ at 5 and $20^{\circ} \mathrm{C} / \mathrm{min}$ heating rate, while the BMPMMDA resin system heat flow values in the range of 0.1 to $0.7 \mathrm{~mW}$ for 5 and $20^{\circ} \mathrm{C} / \mathrm{min}$, respectively. In the case of neat BMPM resin, the heat flow was in the range of 1 to $3.8 \mathrm{~mW}$, indicating an appearance of three distinct activation energy patterns for the three resin systems as a function of percentage conversion. In Figure 4, the $x$ - and $y$-axis scales have been kept constant to emphasize the heat flow characteristics of the three resin systems.

The pure bismaleimide (BMPM) resin undergoes only homopolymerization while curing and this occurs above $180^{\circ} \mathrm{C}$ and continues up to $295^{\circ} \mathrm{C}$. This is the reason behind the relatively sharp peak of the curing reaction. In the second resin system, comprising of BMPM-DABA, it is observed that the peak temperature of the reaction shifts by $15^{\circ} \mathrm{C}$ to higher 
TABLE 1: Key temperature values from DSC plot.

\begin{tabular}{|c|c|c|c|c|}
\hline $\begin{array}{l}\text { Heating rate } \\
\left({ }^{\circ} \mathrm{C} / \mathrm{min}\right)\end{array}$ & $\begin{array}{c}\text { Endotherm } \\
\text { temperature }\left({ }^{\circ} \mathrm{C}\right)\end{array}$ & $\begin{array}{c}\text { Initial cure } \\
\text { temperature }\left({ }^{\circ} \mathrm{C}\right)\end{array}$ & $\begin{array}{l}\text { Peak exotherm } \\
\text { temperature }\left({ }^{\circ} \mathrm{C}\right)\end{array}$ & $\begin{array}{c}\text { Percentage conversion } \\
\text { at peak temperature }\end{array}$ \\
\hline \multicolumn{5}{|c|}{ BMPM } \\
\hline 5 & 162 & 180 & 220 & $58 \%$ \\
\hline 10 & 162 & 200 & 240 & $60 \%$ \\
\hline 20 & 162 & 210 & 250 & $59 \%$ \\
\hline \multicolumn{5}{|c|}{ BMPM with DABA $(1: 1)$} \\
\hline 5 & 120 & 188 & 235 & $55 \%$ \\
\hline 10 & 120 & 200 & 255 & $59 \%$ \\
\hline 20 & 120 & 217 & 260 & $57 \%$ \\
\hline \multicolumn{5}{|c|}{ BMPM with MDA $(3: 2)$} \\
\hline 5 & 90 & 180 & 214 & $56 \%$ \\
\hline 10 & 90 & 188 & 226 & $56 \%$ \\
\hline 20 & 90 & 198 & 233 & $58 \%$ \\
\hline
\end{tabular}

temperature range. This is because bismaleimide undergoes different chemical reactions with DABA, like Ene reaction and Diels-Alder reaction, while curing as shown in Figure 5 $[15,16]$. In the case of the third resin comprising of BMPMMDA, the exothermic peak temperatures are from 6 to $15^{\circ} \mathrm{C}$ lower than that of BMPM. In this case two main reactions are known to be involved; they are the cross-linking reaction of maleimide with secondary amine (Michel addition) and the free-radical homopolymerisation reaction [17]. Figure 6 summaries the two general cure reaction types that can occur in BMPM/MDA resins. The copolymerisation with amine can occur as a step-growth polymerisation, as well as the chain-growth homo-polymerisation with the possibility of two different cross-linking reactions.

The percentage conversion for different heating rates as calculated from the DSC data is shown in Figure 7. As seen, the curves do not intersect, indicating similar cure kinetics at different heating rates. $100 \%$ conversion was achieved at temperatures of 280 to $295^{\circ} \mathrm{C}$ for the three different resin systems.

The multiheating rate technique adopted in this study is an isoconversional method that assumes that the activation energy $\left(E_{a}\right)$ change with conversion. Secondly, from literature [15-17], it is evidenced that the (i) BMPM homopolymerization, (ii) ene reaction, Diels-Alder reaction, and (iii) Michel Addition reaction occurs at significant rates above $180^{\circ} \mathrm{C}$ and within $300^{\circ} \mathrm{C}$ as evident from the DSC exotherms. Therefore, to evaluate the activation energy the temperature range under consideration is in the range of 170 to $300^{\circ} \mathrm{C}$. In this paper the $E_{a}$ values were computed using the equations developed by Ozawa and Kissinger. The activation energy equation according to Ozawa Method is

$$
E_{a}=\frac{-R}{1.052} \frac{\Delta \ln \theta}{\Delta(1 / T p)}
$$

where $\theta$ is the heating rate, $E_{a}$ is the activation energy, and $R$ $=8.314 \mathrm{~J} /{ }^{\circ} \mathrm{K}-\mathrm{mol}$ is the gas constant. Activation energy was calculate from the slope of the plot of $(\ln \theta)$ against $(1 / T p)$.
The activation energy, $E_{a}$ according to the Kissinger method, was obtained from the peak temperature corresponding to the exothermal peak position of the dynamic scan,

$$
\frac{\Delta\left(\ln \left(\theta / T p^{2}\right)\right)}{\Delta(1 / T p)}=\frac{-E_{a}}{R},
$$

where $\theta$ is the heating rate, $E_{a}$ is the activation energy and $R=8.314 \mathrm{~J} /{ }^{\circ} \mathrm{K}-\mathrm{mol}$ is the gas constant. The activation energy can be obtained from the slope of the plot of $\left(\theta / T p^{2}\right)$ against $(1 / T p)$. The results of both these equations, which are essentially dynamic kinetic models are similar as seen in Figure 8 .

Each data point on the $E_{a}$ curve is an average of three values corresponding to three heating rates of 5,10 , and $20^{\circ} \mathrm{C} / \mathrm{min}$, since $E_{a}$ is independent of heating rate and depends only on percentage conversion. The shape of the activation energy curve $E_{a}=f(\alpha)$, indicates directly whether a reaction is simple or complex. For simple processes, it is practically constant as defined by the $n$th order kinetics (NOK) model. The fact that a reaction is governed by constant activation energy does not mean that it is a singlestep reaction. Most probably it is a multistep process that is controlled by the rate of the slowest step as seen in the case of BMPM/MDA. The activation energy remains constant at $108 \mathrm{~kJ} / \mathrm{mole}$ from 10 to $100 \%$ conversion.

The $E_{a}=f(\alpha)$ curve does not reveal the reaction mechanism but will provide significant information about kinetically controlled and diffusion controlled mechanisms. An increase in the activation energy means that more energy is required for the reaction components to complete the reaction in addition to the exothermic reaction indicating an acceleration effect; this phenomenon is exhibited in the case of BMPM/DABA resin system. In the case of BMPM/DABA, the allylphenol compounds diallylbisphenol A (DABA) react with BMPM to give linear chain extension by an ene type reaction and this is followed by a Diels-Alder reaction at a higher temperature. The reaction is complex with 


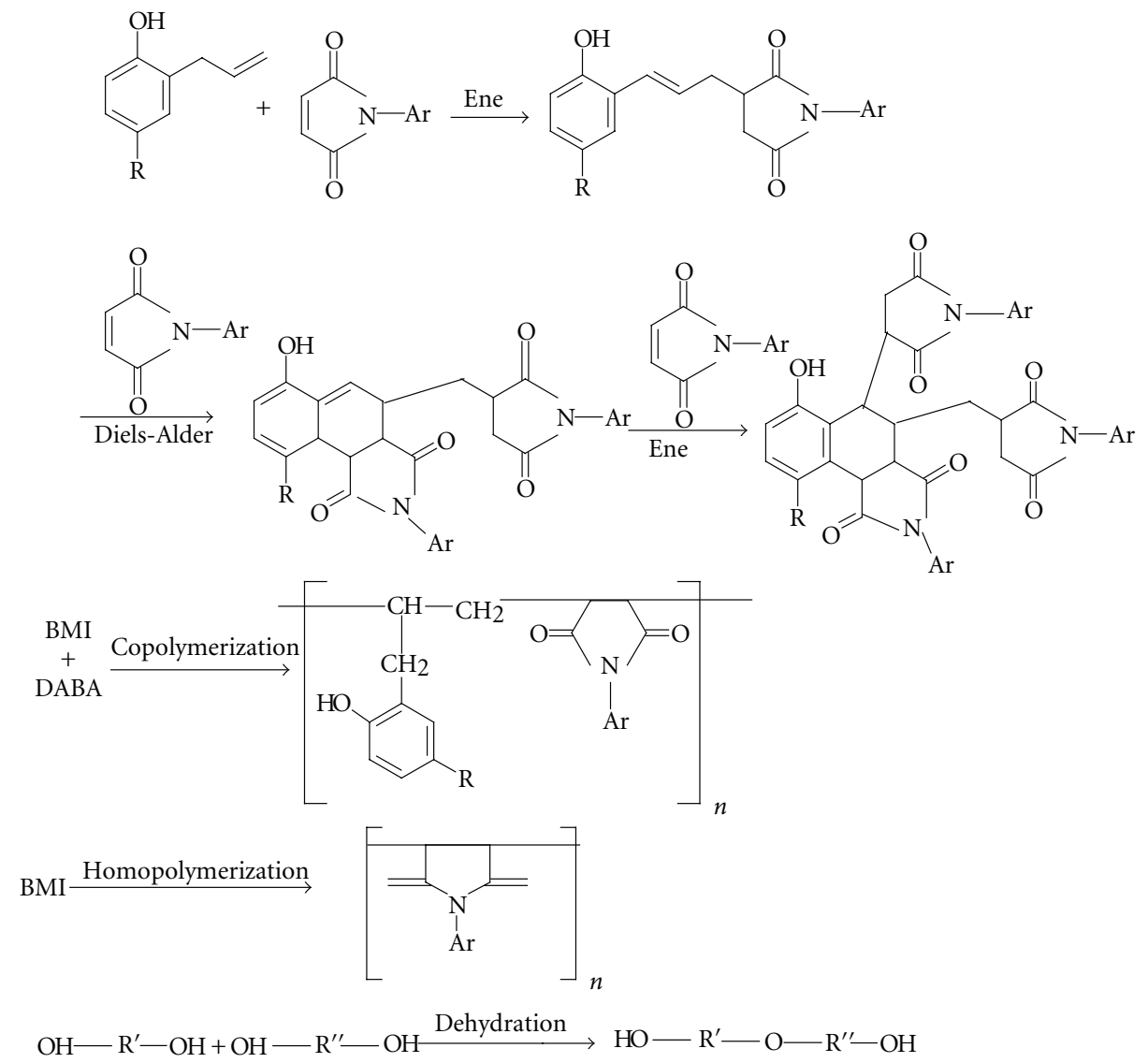

Figure 5: Proposed curing mechanisms of BMI/DABA resins.

Copolymerization<smiles>[R]N1C(=O)CC(N([R])[TlH])C1=O</smiles>

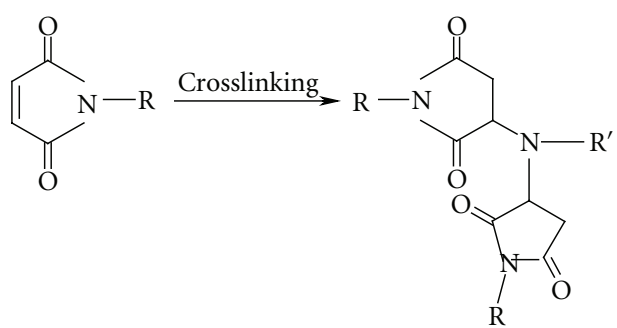

Homopolymerization<smiles>[R]C1CC(=O)N([R])C(=O)C1[R]</smiles>

Figure 6: Proposed curing mechanisms of BMI/MDA resins.

multiple reactions and formation of succinimide groups by the conversion of maleimide moieties occurs [6]. The activation energy steadily increases at approximately $6 \mathrm{~kJ} / \mathrm{mole}$ per percentage conversion. This cure kinetics of this resin system approaches the model-free kinetic (MFK) model.
The difference in the activation energy between Ozawa and Kissinger models is constant at $10 \mathrm{~kJ} / \mathrm{mole}$ and is within the acceptable limits of the two models.

In case of BMPM where complex curing reaction occurs, the activation energy remains constant at $100 \mathrm{~kJ} /$ mole up to 


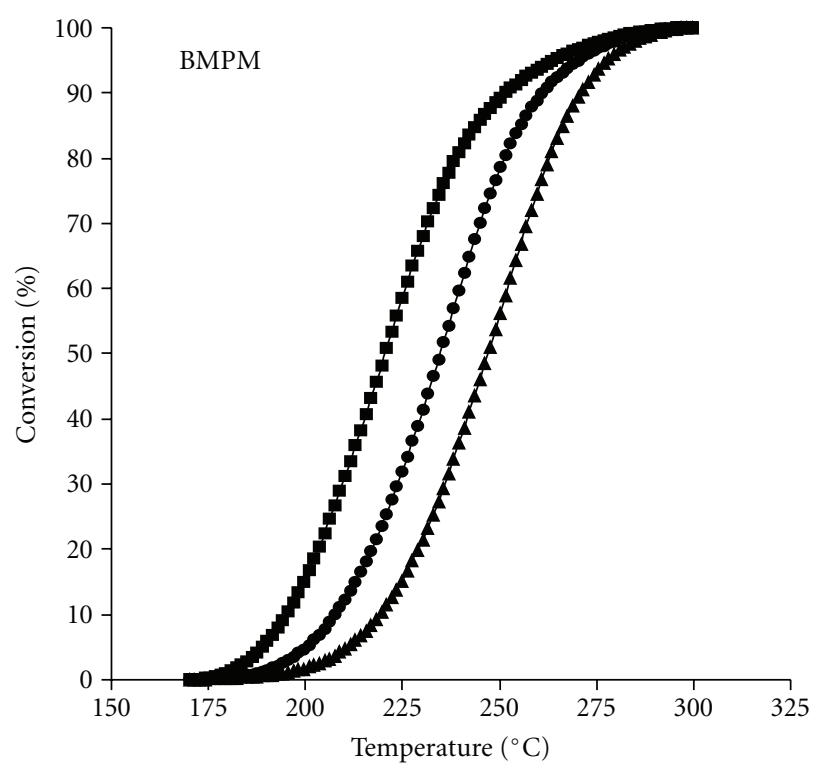

(a)

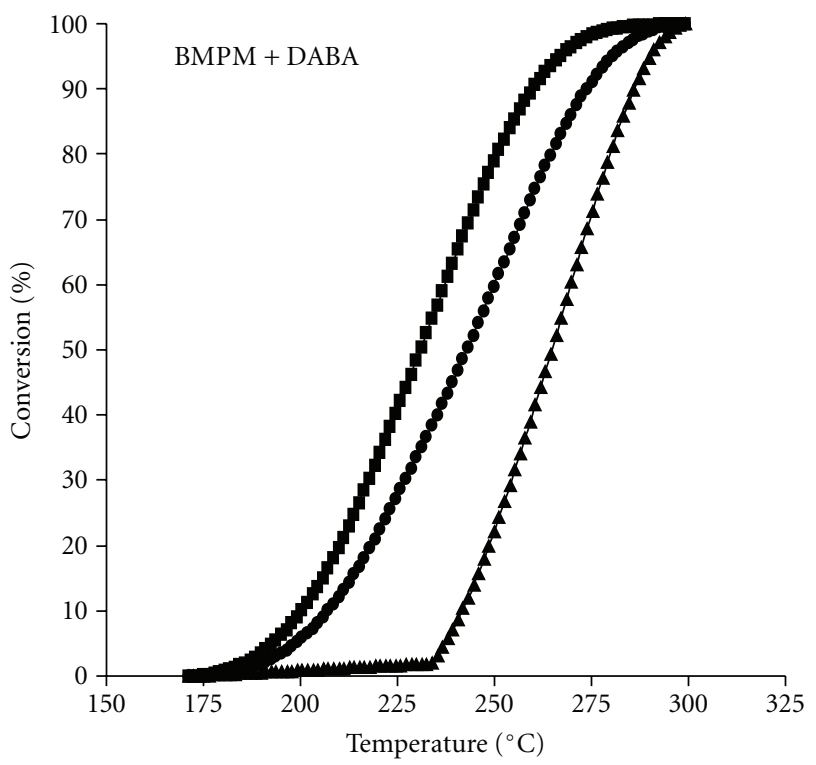

(b)

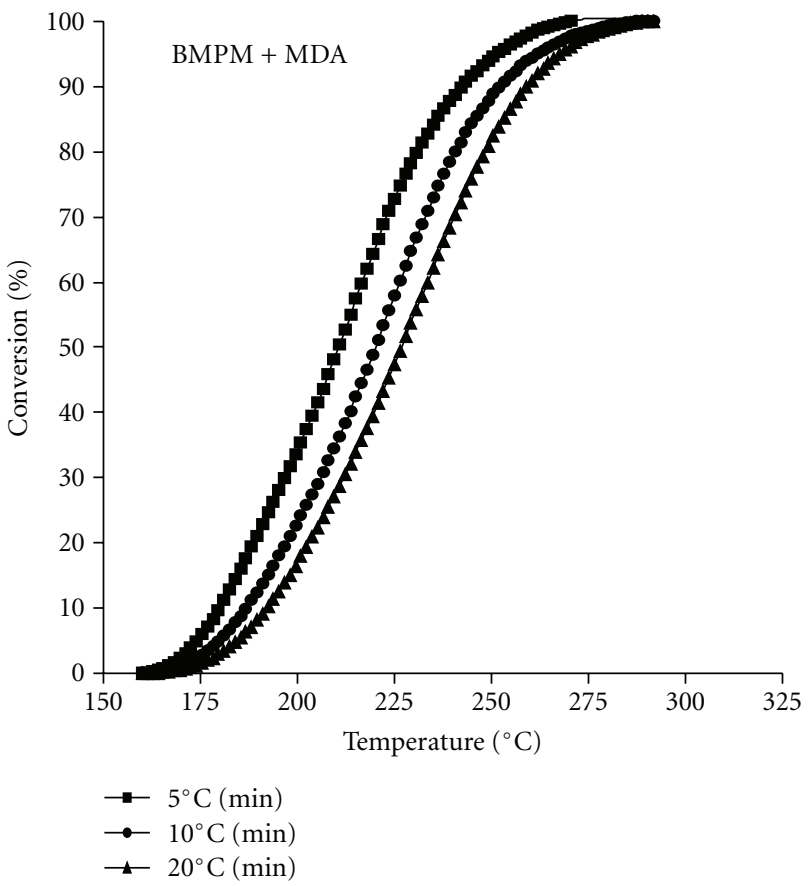

(c)

FIGURE 7: Percentage conversion of BMPM, BMPM/DABA, and BMPM/MDA as a function of temperature.

$60 \%$ conversion. Beyond $60 \%$ conversion the $E_{a}$ curve raises sharply primarily due to higher cross-linking which reduces the molecular mobility and the process changes from being kinetically controlled to diffusion controlled. The activation energy required to achieve $100 \%$ conversion of BMPM resin is $35 \%$ more than that required at $60 \%$ conversion. Thus the homopolymerization of BMPM resin system follows the NOK model upto $60 \%$ cure and MFK model from 60 to $100 \%$.

\section{Conclusion}

The cure kinetics of bismaleimide resins with different chain extenders were investigated by conventional DSC under nonisothermal multi heating rate method. In the case of BMPM/DABA, the activation energy increased steadily from $55 \sim 60 \mathrm{~kJ} / \mathrm{mol}$ to $110 \sim 115 \mathrm{~kJ} / \mathrm{mol}$, as a function of conversion following the model-free kinetics model, while in the case of BMPM/MDA resin system the activation energy 


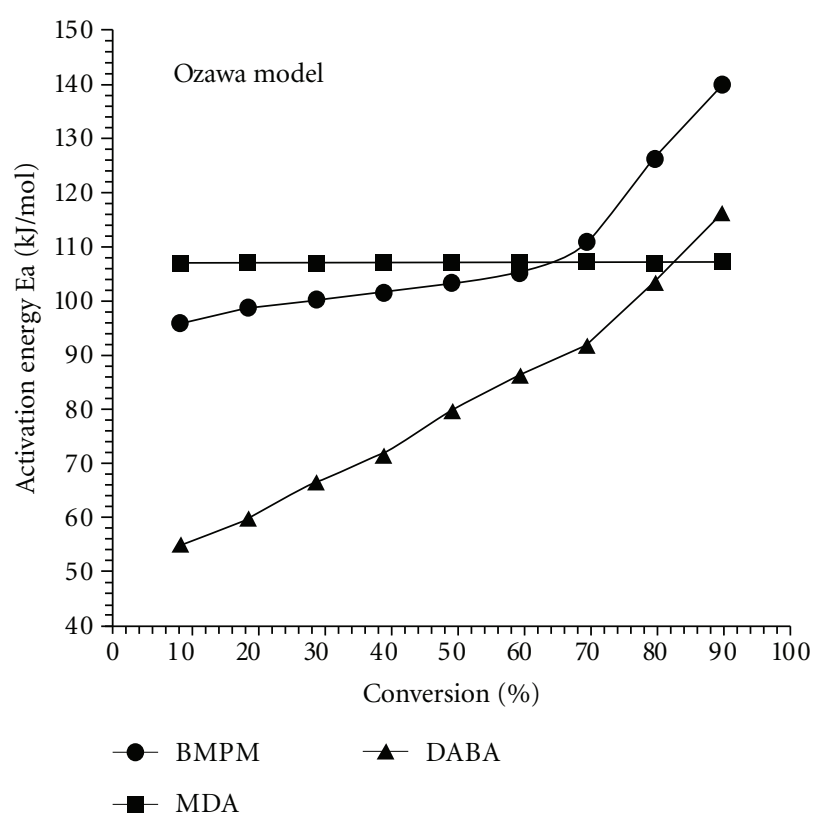

(a)

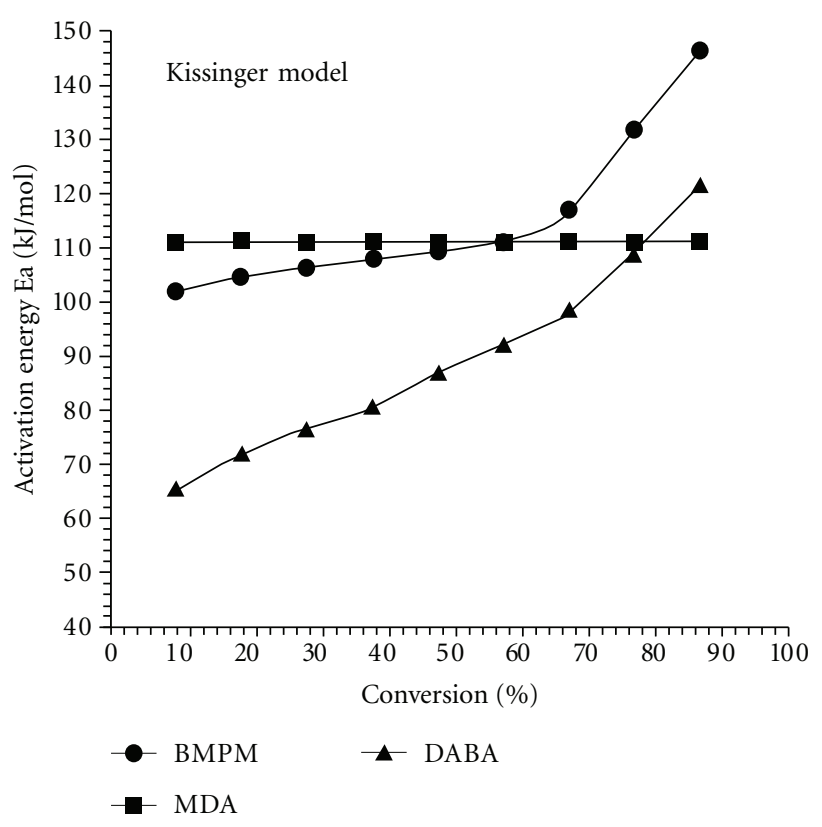

(b)

Figure 8: Activation energy $\left(E_{a}\right)$ as a function of conversion for BMPM, BMPM/DABA, and BMPM/MDA.

remained constant at $108 \mathrm{~kJ} / \mathrm{mole}$ as per the $n$th order kinetics approach. BMPM neat resin, showed a combination of constant activation energy up to $60 \%$ conversion and steep rise from 60 to $100 \%$, reaching a maximum value of $140 \mathrm{~kJ} / \mathrm{mole}$.

\section{Acknowledgment}

The authors wish to thank the authorities of Naval Research Board, New Delhi, for providing the financial support for this research work under the project titled "innovative approaches for improving the hot-wet performance of bismaleimide/carbon composites" (NRB-134/MAT/07-08).

\section{References}

[1] H. Qin, P. T. Mather, J.-B. Baek, and L.-S. Tan, "Modification of BisphenolA based bismaleimide resin(BPA-BMI) with allyl terminated hyper branched polyimie(ATPAEKI)," Polymer, vol. 47, pp. 2813-2821, 2006.

[2] Y. Li, J. Miranda, and H.-J. Sue, "Hygrothermal diffusion behaviour in bismaleimide resin," Polymer, vol. 42, pp. 77917799, 2001.

[3] H. Tang, N. Song, Z. Gao et al., "Synthesis and properties of 1,3,4-oxadiazole-containing high-performance bismaleimide resins," Polymer, vol. 48, no. 1, pp. 129-138, 2007.

[4] J. N. Hay and P. O'Gara, "Recent developments in thermoset curing methods," Proceedings of the Institution of Mechanical Engineers G, vol. 220, no. 3, pp. 187-195, 2006.

[5] M. E. Wright and D. A. Schorzman, "Thermally curing arylethynyl end-capped imide oligomers: study of new aromatic end cap," Macromole, vol. 33, pp. 8611-8617, 2000.
[6] Y. Xiong, F. Y. C. Boey, and S. K. Rath, "Kinetic study of the curing behavior of bismaleimide modified with diallylbisphenol A," Journal of Applied Polymer Science, vol. 90, no. 8, pp. 2229-2240, 2003.

[7] D. Roşu, C. N. Caşcaval, F. Musta, and C. Ciobanu, "Cure kinetics of epoxy resins studied by non-isothermal DSC data," Thermochimica Acta, vol. 383, no. 1-2, pp. 119-127, 2002.

[8] Z. Guo, S. Du, B. Zhang, and Z. Wu, "Cure kinetics of T700/BMI prepreg used for advanced thermoset composite," Journal of Applied Polymer Science, vol. 97, no. 6, pp. 22382241, 2005.

[9] Z. S. Guo, S. Y. Du, B. M. Zhang, and Z. J. Wu, "Modeling the curing kinetics for a modified bismaleimide resin using isothermal DSC," Journal of Applied Polymer Science, vol. 92, no. 5, pp. 3338-3342, 2004.

[10] R. Seifi and M. Hojjati, "Heat of reaction, cure kinetics, and viscosity of araldite LY-556 resin," Journal of Composite Materials, vol. 39, no. 11, pp. 1027-1039, 2005.

[11] J. Mijovic and S. Andjelic, "Study of the mechanism and rate of bismaleimide cure by remote in-situ real time fiber optic nearinfrared spectroscopy," Macromolecules, vol. 29, pp. 239-246, 1996.

[12] M. Harsch, J. Karger-Kocsis, and M. Holst, "Influence of fillers and additives on the cure kinetics of an epoxy/anhydride resin," European Polymer Journal, vol. 43, no. 4, pp. 1168-1178, 2007.

[13] J. Schawe, "Kinetic studies of complex reactions-part 1: model free kinetics Usercom," Mettler-Toledo, vol. 18, pp. 1316, 2003.

[14] J. Schawe, "Kinetic studies of complex reactions-part 2: description of description control, Usercom," Mettler Toledo, vol. 18, pp. 8-12, 2004.

[15] R. J. Morgan and R. J. Jurek, “Toughening procedures, processing and performance of bismaleimide-carbon fibre composites," Polymer, vol. 34, no. 4, pp. 835-842, 1993. 
[16] Y. Li, Synthesis and cure characterization of high temperature polymers for aerospace applications, Ph.D. thesis, Dept.of Materials Science and Engineering, Texas A\&M University, 2004.

[17] J. L. Hopewell, G. A. George, and D. J. T. Hill, "Quantitative analysis of bismaleimide-diamine thermosets using near infrared spectroscopy," Polymer, vol. 41, no. 23, pp. 82218229, 2000. 

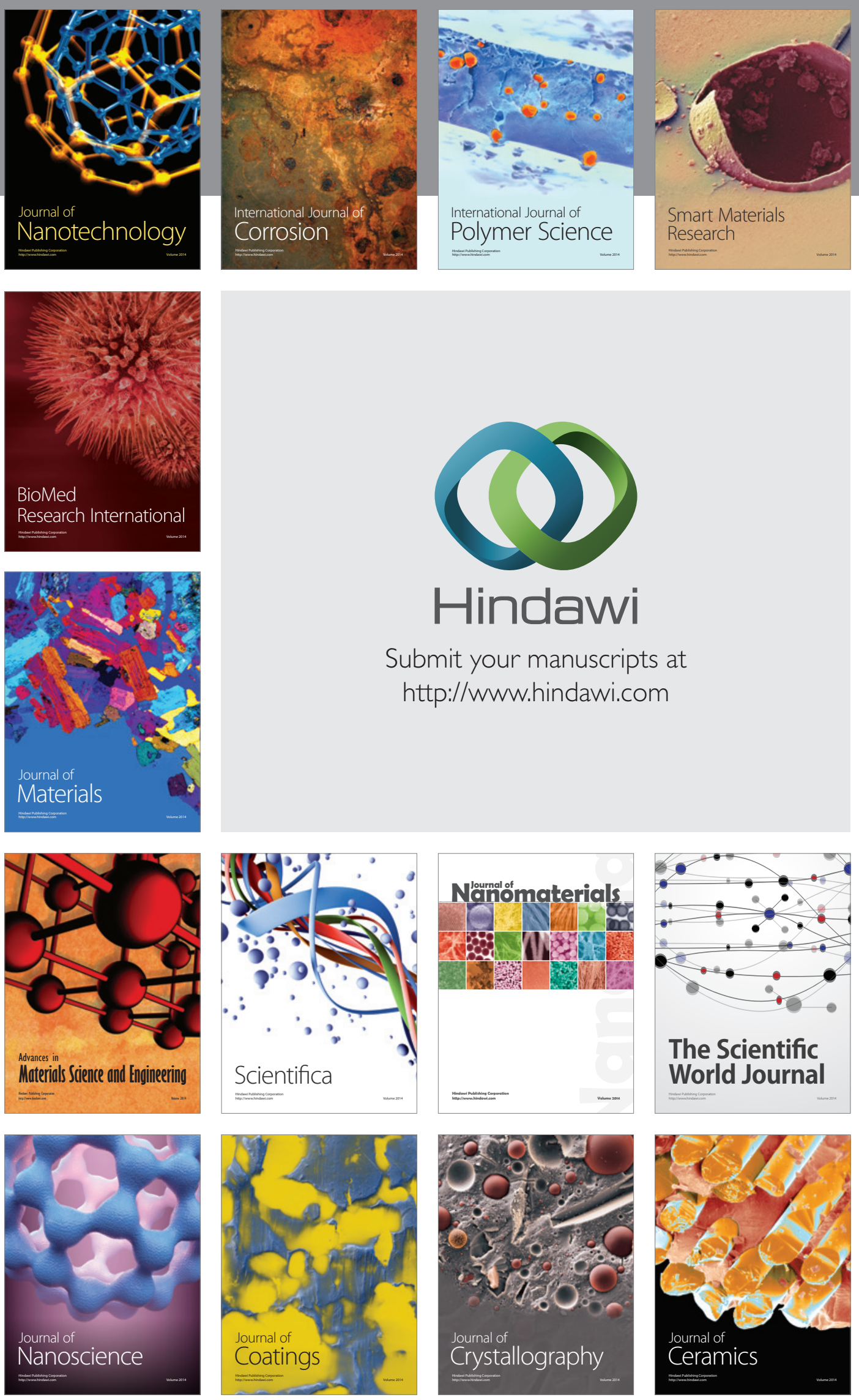

The Scientific World Journal

Submit your manuscripts at

http://www.hindawi.com

\section{World Journal}

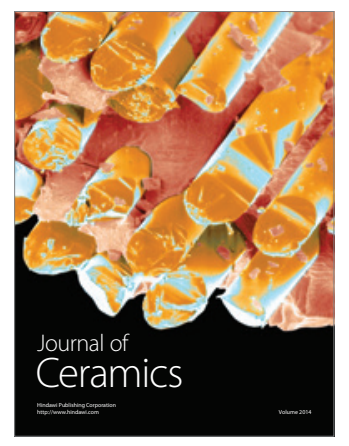

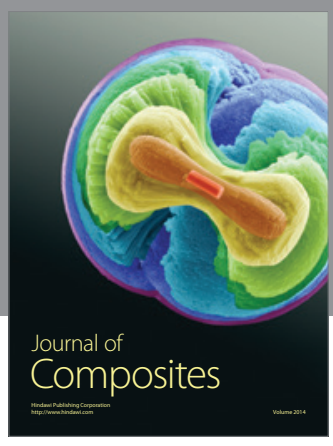
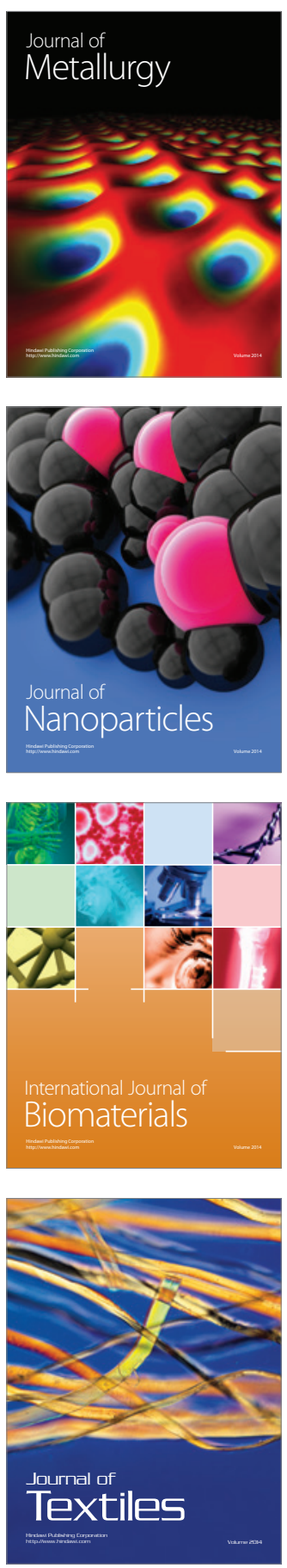